\title{
Successful transfemoral core valve aortic valve implantation in a patient with degenerated solofreedom biologic supravalvular aortic valve
}

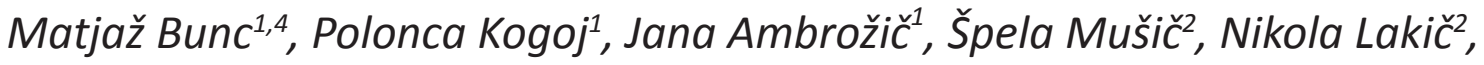 \\ Borut Geršak ${ }^{2}$ \\ ${ }^{1}$ Department of Cardiology, University Medical Centre Ljubljana, Zaloška c. 007, 1000 Ljubljana, ${ }^{2}$ Department for Cardio and \\ Vascular Surgery, University Medical Centre Ljubljana, ${ }^{3}$ Department of Radiology, University Medical Centre Ljubljana, Zaloška \\ c. 007, 1000 Ljubljana, ${ }^{4}$ Institute for Pathopysilogy, School of Medicine, Zaloška c.002, 1000 Ljubljana
}

Abstract

Percutaneous aortic valve implantation (TAVI) is well established treatment option for high risp patients with severe aortic stenosis. Transcatheter aortic valve implantation (TAVI) is an attractive treatment option for patients with failing bioprostheses (valve-in-valve concept), especially in elderly patients with high risk for reoperation. Although clinical experience is still limited for this off-label indication, the procedure has been shown to be feasible in stented as well as stentless bioprostheses. We report a case of of 71-years old woman were CoreValve $23 \mathrm{~mm}$ (Medtronic, Inc., Minneapolis, Minnesota, USA) was implanted inside a degenerated Sorin Freedom SOLO bioprosthesis using transfemoral approach. Freedom SOLO bioprosthesis stentless bioprosthesis is sutured in supra-annular position and presents a TAVI challenge due to its proximity to coronary ostia. Careful pre-procedural planning with TEE and CTA is crucial. We decided for transfemoral approach with $23 \mathrm{~m}$ CoreValve implantation. Balloon valvuloplasty before TAVI with contrast injection may predict the final result and is helpful for procedure success and risk reduction. The final TAVR result was good. This case proves the ViV concept for stentless Freedom SOLO bioprosthesis.

Key words TAVI, SOLO Freedom, stentless bioprosthesis, degeneration, valve in valve

\section{Background}

$\mathrm{T}$ he most effective treatment for patients with severe symptomatic aortic stenosis is surgical replacement of the valve. ${ }^{1}$ Aortic valve replacement with a bioprosthesis is preferred, especially in older populations, due to its satisfactory hemodynamic performance without warfarin related complications. Sorin Freedom SOLO bioprosthesis (Sorin Biomedica Cardio, Saluggia, Italy) is implantated in the supra-annular position. According to available data the SOLO valve is durable with good hemodynamic performance and low complication rates..$^{2-4}$ In our institution more than 500 implantations were performed in the last 8 years. ${ }^{5}$ It should not be unexpected that a considerable number of patients may require reintervention due to a dysfunctional bioprosthesis with structural valve deterioration. Surgical treatment of degenerated aortic bioprostheses is associated with an increased risk of morbidity and mortality, especially in elderly patients with significant co-morbidities. Therefore, transcatheter aortic valve implantation (TAVI) performed as valve in valve (VIV) technique appears as an attractive alternative treatment option. ${ }^{6-9}$ Pericardial stentless aortic biopro- sthesis Freedom Solo represents a challenge for VIV implantation due to its supra-annular position potentially leading to coronary obstruction.

We report a case of ViV implantation by transfemoral approach with a 23-mm self-expandable prosthesis CoreValve (Medtronic, Inc., Minneapolis, Minnesota, USA) inside a degenerated Sorin Freedom SOLO bioprosthesis.

\section{Case presentation (Core Valve in Freedom Solo valve)}

71-years old woman underwent surgical aortic valve replacement with a $25-\mathrm{mm}$ Freedom Solo bioprosthesis in 2007. During the same surgical procedure bypass graft with left internal mammary artery (LIMA) left to LAD and venous grafts to the first (OM1) and second (OM2) obtuse marginal coronary artery was also done. Five years after the surgery she presented to our institution with dispnea (New York Heart Association functional class II to III). Echocardiographic examination revealed degeneration of the aortic bioprosthesis (mean gradient across the aortic valve of $28 \mathrm{mmHg}$ and aortic valve area of 0.83 $\mathrm{cm}^{2}$ ). She refused any other further evaluation and tre- 
A

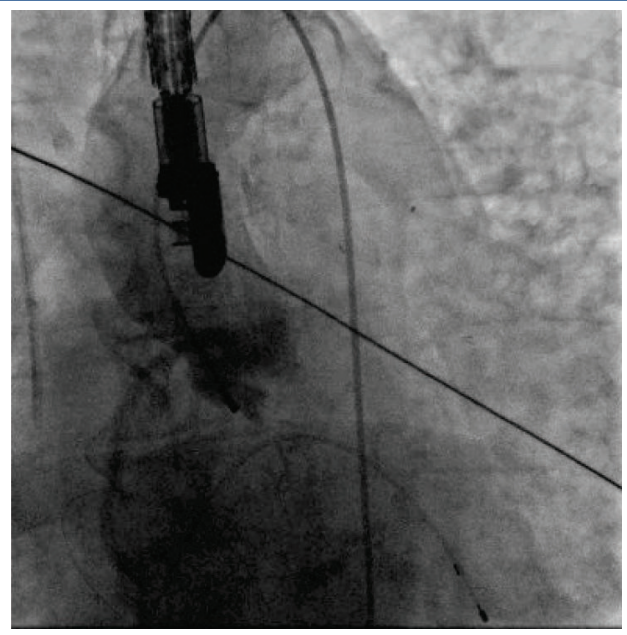

C

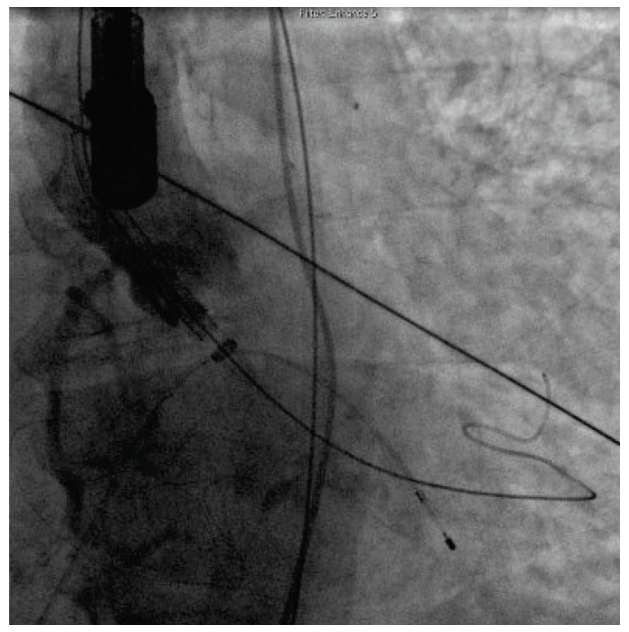

B

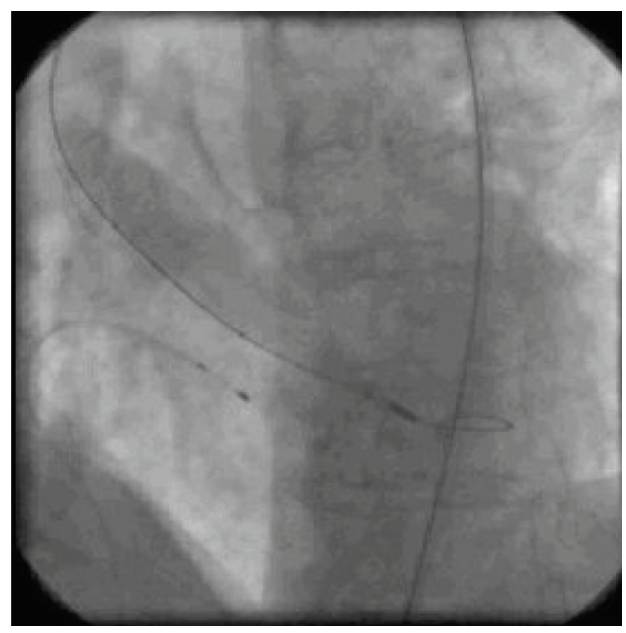

D

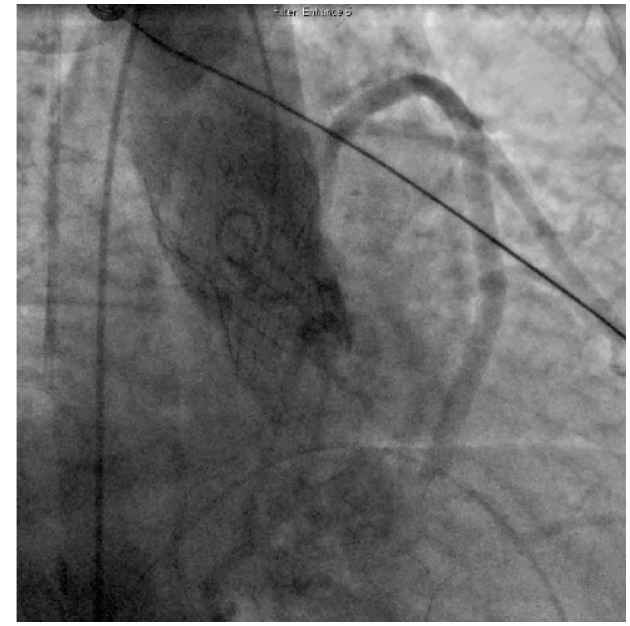

Figure 1: Valve in valve implantation

A. Orthogonal view before baloon valvuloplasty B. Baloon valvuloplasty

C. Valve positioning D. Final angiographic result

atment and was discharged. She presented again after one year with severe heart failure. An echocardiogram revealed a progression of the biologic aortic valve degeneration with severe aortic stenosis (mean gradient of 50 $\mathrm{mmHg}$, aortic valve area of $0.6 \mathrm{~cm}^{2}$ ) and mild to moderate aortic regurgitation. The global systolic function of the left ventricle was preserved with the ejection fraction of $65 \%$. A severe pulmonary hypertension of $85 \mathrm{mmHg}$ was also found. Cardiac catheterization showed patent coronary artery bypasses with no new significant disease on other coronary arteries. Due to several comorbidities (chronic obstructive pulmonary disease with severe obstructive and restrictive respiratory failure, chronic renal disease, diabetes on insulin, severe obesity, previous cardiac surgery) the surgical risk was high (logistic Euroscore of $31 \%$ ) and she was refused for aortic valve re-replacement. TAVI was considered and shown to be feasible after morphological evaluation with multidetector computed tomography and transesophageal echocardiography.

One week after the admission we performed the percutaneus procedure under general anestesia. First we inserted a SPIDER Embolic Protection Device in the right internal carotid artery to prevent embolic events. Then balloon aortic valvuloplasty with aortic angiography was done for the final valvular sizing and to explore the anatomical relation of the opened surgical prosthesis leaflets to the coronary ostia (Figure $1 \mathrm{~B}$ ). After the vuloplasty a 23-mm self-expandable CoreValve (Medtronic, Inc., Minneapolis, Minnesota, USA) was implanted via femoral access (Figure $1 \mathrm{C}$ ). The transcatheter prosthesis was expanded during rapid pacing under fluoroscopic and transesophageal guidance. The final angiographic result was excellent, showing good opening of the trancatheter valve leaflets and fully patent coronary ostia (Figure $3 \mathrm{D}$ ). Echocardiogram after implantation showed good hemodynamic properties of the transcatheter valve with a maximal gradient of 20 $\mathrm{mmHg}$, estimated aortic valve area of $1.7 \mathrm{~cm}^{2}$ and mild paravalvular regurgitation (Figure 2).

\section{Discussion}

Increased life expectancy and improvement in clinical outcome following surgery has led to an increasing number of elderly patients with a history of prior aortic valve replacement (AVR). As a consequence, a considerable number of patients may require reintervention due to a dysfunctional bioprosthesis with structural valve deterioration. Transcatheter aortic valve implantation (TAVI) has become an established surgical alternative in patients 


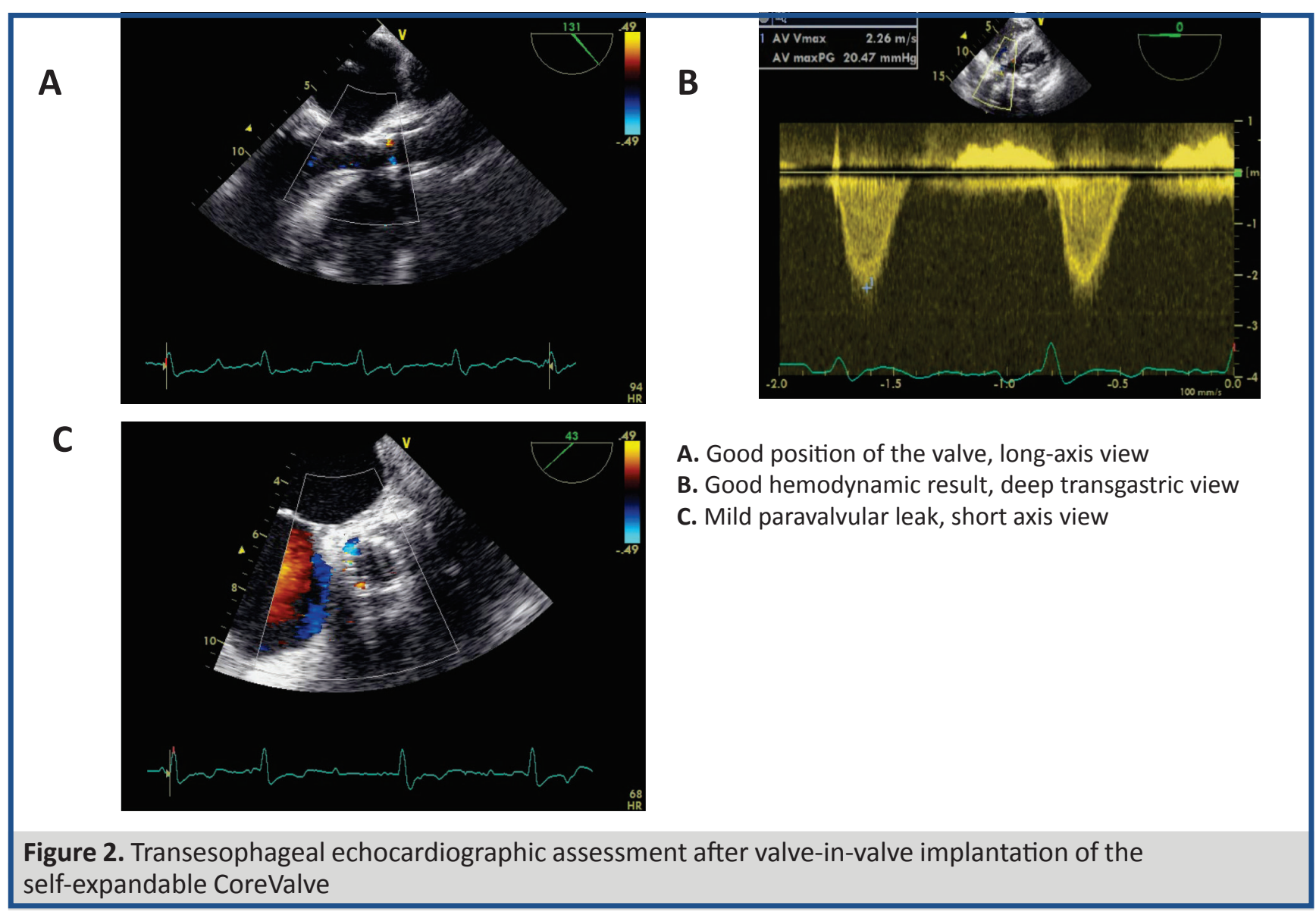

with aortic stenosis and severe comorbidities. Freedom Solo aortic valve is stentless bioprosthesis that is implanted in a supravalvular position, which is particularly beneficial in elderly patients with severely calcified aortic valves rendering difficult the conventional implantation in the annular position. . $^{2,3}$

During valve-in-valve implantation supra-annular bioprosthetic position presents a technical challenge since bioprosthetic leaflets may extent to aortic wall and potentially obstruct coronary ostia. Careful pre-procedural planning with multidetector computed tomography and three-dimensional transesophageal echocardiography is important for the assessment of aortic root anatomy, relationship of the bioprosthetic leaflet height in relation to coronary ostia and size of the prosthesis orifice..$^{10,11}$ In addition, balloon valvuloplasty before TAVI is useful for checking the position of the opened bioprosthetic leaflets in relation to coronary ostia and for final valvular sizing.

In the reported case we have shown that valve-in-valve procedure for failing supra-annular bioprosthesis Freedom Solo is feasibile, considering technical difficulties.

\section{References}

1. Vahanian A, Alfieri O, Andreotti F et al. Guidelines on the management of valvular heart disease (version 2012): The joint task force on the management of valvular heart disease of the European Society of Cardiology (ESC) and the European Association for Cardio-Thoracic Surgery (EACTS). Eur Heart J 2012;33:2451-96.

2. Aymard T, Eckstein F, Englberger L, Stalder M, Kadner A, Carrel T. The Sorin Freedom SOLO stentless aortic valve: technique of implantation and operative results in 109 pa-tients. J Thorac Cardiovasc Surg 2010;139(3):775-7.
3. Altintas G, Ilkay Diken A, Hanedan O, Yurdakok O, Ozyalcin S, Kucuker SA, Ozatik AMThe Sorin Freedom SOLO Stentless Tissue Valve. ex Heart Inst J 2013;40(1):50-5.

4. Beholz S, Claus B, Dushe S, Konertz W. Operative technique and early hemodynamic results with the Freedom Solo valve. J Heart Valve Dis 2006;15(3):429-32.

5. Gersak B, Gartner U, Antonic M. Thrombocytopenia following implantation of the stentless biological Sorin Freedom SOLO valve. J Heart Valve Dis 2011;20(4):401-6.

6. Dvir D, Barbanti M, Tan J, Webb JG. Transcatheter aortic valve-invalve implantation for patients with degenerative surgical bioprosthetic valves. Curr Probl Cardiol. 2014 Jan;39(1):7-27.

7. Dvir D, Webb J, Brecker S, Bleiziffer S, Hildick-Smith D, Colombo A, Descoutures F, Hengstenberg C, Moat NE, Bekeredjian R, Napodano $M$, Testa L, Lefevre T, Guetta $V$, Nissen $H$, Hernández JM, Roy D, Teles RC, Segev A, Dumonteil N, Fiorina C, Gotzmann M, Tchetche D, Abdel-Wahab M, De Marco F, Baumbach A, Laborde JC, Kornowski R. Transcatheter aortic valve replacement for degenerative bioprosthetic surgical valves: results from the global valve-in-valve registry. Circulation. 2012 Nov 6;126(19):2335-44.

8. Azadani AN, Tseng EE. Transcatheter heart valves for failing bioprostheses: state-of-the-art review of valve-in-valve implantation. Circ Cardiovasc Interv 2011;1;4(6):621-8.

9. Bapat V, Attia R, Redwood S, Hancock J, Wilson K, Young C, Thomas M. Use of transcatheter heart valves for a valve-in-valve implantation in patients with degenerated aortic bioprosthesis: technical considerations and results. J Thorac Cardiovasc Surg. 2012 Dec;144(6):1372-9; discussion 1379-80.

10. Bapat VN, Attia R, Thomas M. Effect of Valve Design on the Stent Internal Diameter of a Bioprosthetic Valve: A Concept of True Internal Diameter and Its Implications for the Valve-in-Valve Procedure. JACC Cardiovasc Interv. 2014 Jan 9. pii: S19368798(13)01677-4.

11. Bapat VN, Attia RQ, Condemi F, Visagan R, Guthrie M, Sunni S, Thomas M. Fluoroscopic guide to an ideal implant position for Sapien XT and CoreValve during a valve-in-valve procedure. JACC Cardiovasc Interv. 2013 Nov;6(11):1186-94. 